\title{
ROLE OF SOCIAL MEDIA IN CREATION OF AWARENESS FOR SUSTAINABLE DEVELOPMENT GOAL IN HIGHER EDUCATION
}

\section{RUMA SAHA \& Dr. SHARMILA KAYAL}

Assistant Professor, Department of Journalism \& Mass Communication, Adamas University, Barasat, Kolkata, India

Social media has ushered in a new age in creating sustainable development goal (SDG) especially in higher education. New media has contributed a lot in equalizing flow of information which assist in sustainable development. In developing countries like India and other south-east Asian country ICT and its associated infrastructural development has been improved rapidly to connect and reach people. The reach of this media has increased in recent times especially among college goers. Therefore, new media has the capacity to influence and set agenda with SDG in respect to education at higher level. The methodology for this research is quantitative in nature. Data collection is to be done through survey method and the respondents are chosen by simple random method. The objective of this research is to find out how student fraternity at higher education level adopt new media to het aware about sustainable development goal. The result of the research showed level of awareness about SDG among students of higher education. Through social media, a large percentage of students are participating in promoting SDG awareness unknowingly. They are not aware of the terminology like sustainable development goal but are aware of the activities which are associated with sustainable development goal.
\end{abstract}

KEYWORDS: Social Media, SDG, Higher Education, Adaptation \& India

Received: Mar 06, 2019; Accepted: Apr 26, 2019; Published: May 22, 2019; Paper Id.: IJCMSJUN201914

\section{INTRODUCTION}

Sustainable Development Goal is also called Global Goal as it is meant to address and call for action to eradicate poverty, save planet earth and ensure peace in the world. United nation has undertaken 2030 agenda for sustainable development in 2015 meeting along with its member states. The purpose is promote and encourage peace and prosperity for people as well as for planet earth for present and future (Background of the Sustainable Development Goals, n.d.).

In 1992, Earth Summit was held in Rio de Janeiro, Brazil where member countries of UN has adopted Agenda 21aimed at building global partnership to bring sustainable development to protect environment and improve human life (Sustainable Development Knowledge Platform, n.d.).

In the year 2000 another meeting took place in New York where member states of UN had adopted Millennium Development Goal to reduce extreme poverty within 2015.

In the year 2012 UN conference was held at Rio de Janeiro. The conference was on Sustainable development and the outcome emphasised the member states to adopt SDG as part of their future program of work in developing nation (Sustainable Development Knowledge Platform, n.d.). 
This paper aims to study how SDG is dealt in India. The study reveals how people especially future generation is aware about SDG in a developing nation like India so as to work for its' purpose. ICT and new media curved a new path for spreading awareness about SDG among people especially younger generation like students of higher education level.

\section{LITERATURE REVIEW}

Research is done on "Environmental Education for Sustainability: defining the new focus of environmental education in the 1990s" by Daniella Tilbury in 2006. Researcher tried to focus on the changes in environmental education that took place after 1990s especially focuses on what constitute this environmental education. In 1990s a new approach was developed towards environmental studies for encouraging sustainability. This design was of study was aimed to start from school level and it claimed to be different from 1980s approach of environmental studies (Tilbury, 1995).

Recent research is done on "The Role of Information and Communication Technology (ICT) and Higher Education in Sustainable Development" by Adu et.al in 2014. Researcher examined the role of ICT and higher education in bringing sustainable development in Nigeria. Researchers focuses on how ICT and higher education increase sustainability. The methodology followed was quantitative. Survey was done on university level educator, questions were divided into three sections to investigate the research question (Adu et.al., 2014).

Research is done on "Neoliberalism, new public management and the sustainable development agenda of higher education: history, contradictions and synergies" by Bessant et.al in 2015. Researchers tried to explore practical and ideological relationship between New Public Management (NPM) and neo-liberalism along with SDG agenda for higher education. Researcher had based their field study on higher education system in UK. Researchers examine synergies and contradiction between neo-liberalism and NPM also to find out how sustainable development agenda in higher education is practiced in English University. Researchers through this research tried to reveal the challenges and opportunities in respect to sustainable development in education system in the context of neo-liberalism (Bessant et.al., 2015).

Research is done on "Education for sustainable human development: Towards a definition" by Landorf et.al in 2008. Researchers in this article tried to examine the concept and implementation of education for sustainable development (ESD) in the context of 'human capability approach'. Researchers in this paper had attempted to define ESD as educational practice developed for increasing human well-being in their individual capability basis. This in turn encourages individual to participate in democratic dialogues and discussion for now as well as for future generation. Researchers concluded that by incorporating 'human capability approach' propounded by Dr. Amartya Sen (Nobel laureate economist) into ESD will provide comprehensive guidance and clear direction needed for the purpose of transforming curriculums and pedagogy (Landorf et.al., 2008).

\section{RESEARCH QUESTION}

RQ1. How SDG is handled in higher education sectors by the students?

RQ2. What role does new media plays in respect to students' contribution to SDG in India?

RQ3. Does ICT development involved student fraternity in higher education level to know more about SDG and contribute to its' growth in Kolkata?

RQ4. Do new media initiate in higher education through students a sense of SDG in urban areas near Kolkata? 


\section{RESEARCH OBJECTIVE}

- To explore if young generation especially students at higher education level is aware about SDG in this age of digitization.

- To study the contribution of new media in encouraging students of college and university level to understand and contribute towards SDG.

\section{RESEARCH METHODOLOGY}

Quantitative methodology is applied in this research. Exploratory research design is used. Survey method is adopted for collecting data in this study. Survey is conducted among university level students of undergraduate as well as post-graduate level. Samples in this survey are selected in random sampling method. Questionnaire is prepared and validated.

Survey is divided into two parts. In first part it is evaluated the new media usage habit of respondents and how ICT contribute to development of awareness among students about SDG.

Secondly, to learn whether students at higher education level in India especially Kolkata and suburbs are aware of SDG. This part of survey is dedicated to find out popular medium of getting aware of SDG and also to explore their attitude towards SDG.

Survey is done on college and university level students. Simple random sampling method is used in selecting students. Total sample size is 100 students of private university in suburb of Kolkata and from government aided college of same area. Department surveyed are Journalism and Mass Communication, Economics, Management, MBA, MA.

\section{RESULTS AND DISCUSSIONS}

In the first part of the survey study is done on social media usage behaviour or habits of students.

\section{Gender Ratio of Social Media Usage of Students at University Level}

In that it is seen that all the respondents use social media out of which $60 \%$ are female user and $40 \%$ are male user. Figure 1 shows graphical representation of the same.

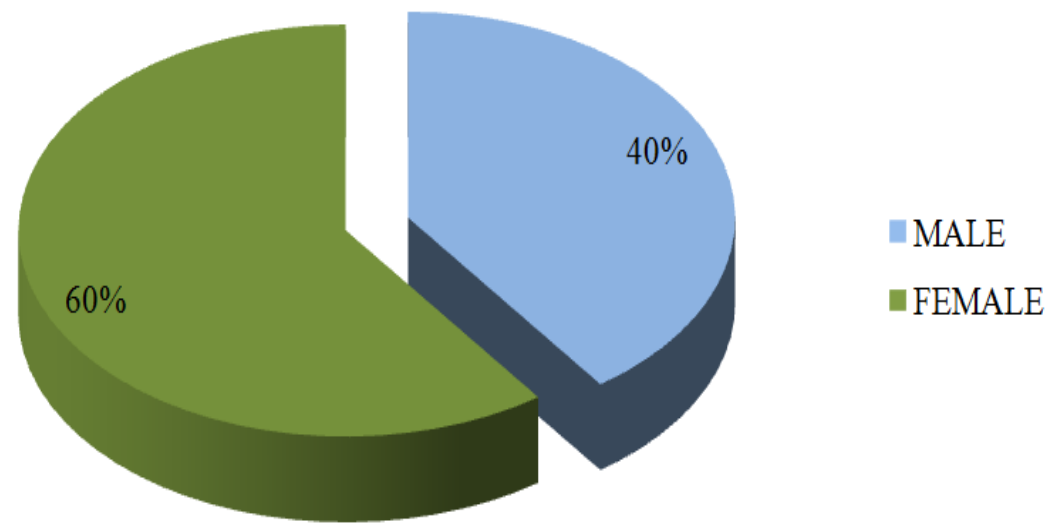

Figure 1: Gender Ratio of Social Media Usage of Respondents

Check the table 1 to understand the social media usage percentage of respondents. 


\section{Most Popular Social Media to the Students}

Respondents are asked to rank in a scale of five according to their level of preference. Likert scale is used for measurement of this item to identify the most popular social media among college and university level students. Figure 2 gives a graphical representation of the popularity ranking of five social media (Facebook, LinkedIn, Instagram, Google+, Twitter). Y-axis defines the percentage of respondents ranked items mentioned in $\mathrm{X}$-axis in first place in their ranking scale.

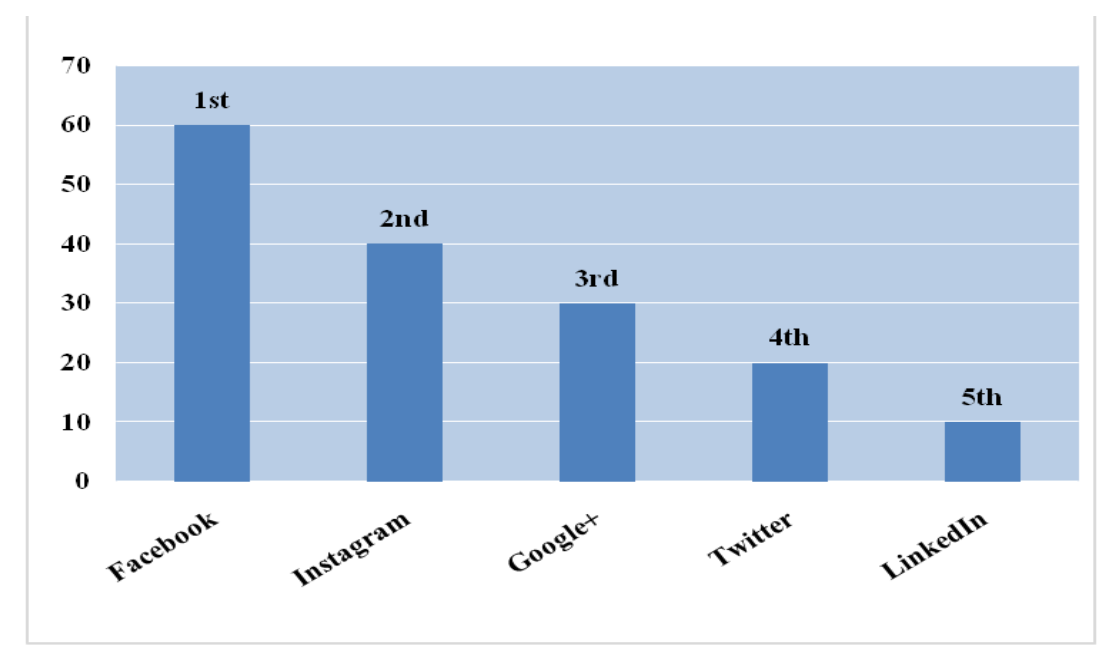

Figure 2: Most Popular Social Media to the Students

Check the table 2 to understand the social media usage preference popularity ranking among student.

\section{Topic Interested Most to the Students in Social Networking Sites}

Respondents were asked to choose the topic most interesting to them in social media. Figure -3 shows graphical representation of percentage of respondents interested in topics mentioned in the question, while they use social networking sites.

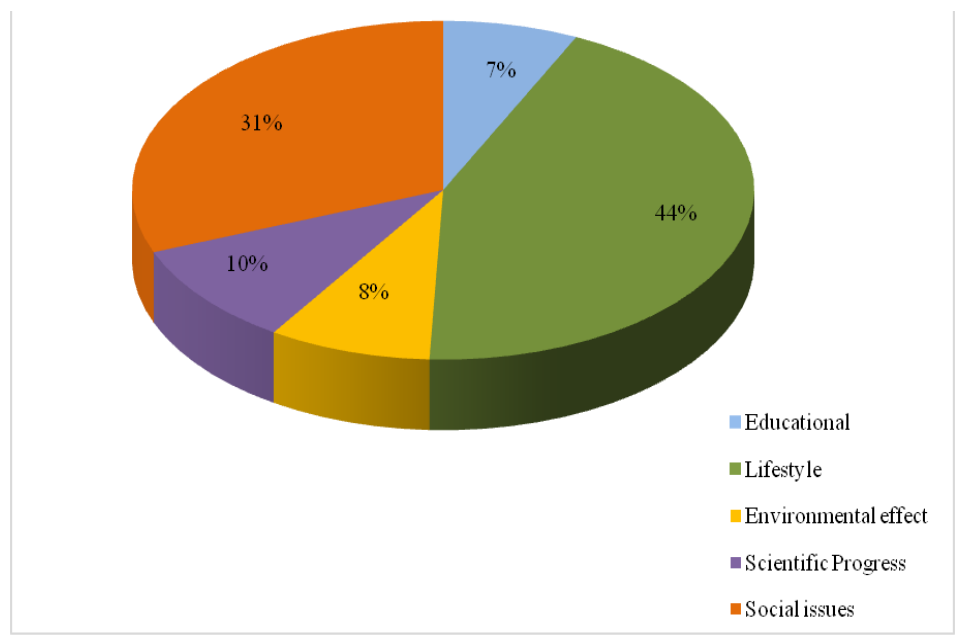

Figure 3: Topic Interested Most to the Students in Social Networking Sites

Check the table- 3 to understand the percentage of respondents interested in different topics mentioned in the question when the respondent use social networking sites. 


\section{Participation Level in Virtual Community Dedicated to Environment Protection}

Respondents are asked to answer in dichotomy about whether they participate and become member of any virtual community dedicated to environment protection. Figure-4 shows graphical representation of percentage of respondents participated in virtual community dedicated to environment protection.

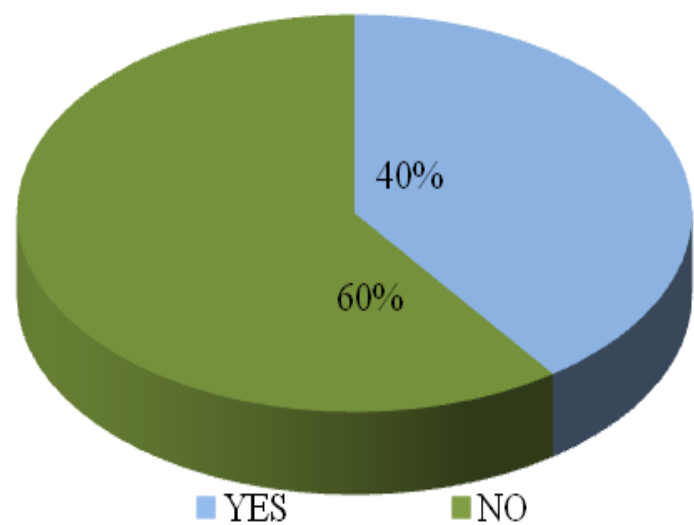

Figure 4: Participation in Virtual Community Dedicated to Environment Protection

Check the table- 4 to understand the percentage of respondents participates in virtual community dedicated to environment protection. The second section of survey explores whether students of higher education level in India are aware of SDG and role of social media in creating SDG awareness among students.

\section{Whether there is Existing Knowledge about the Term SDG Among Respondents?}

Respondents were asked whether they heard the term "Sustainable Development Goal" (SDG) prior to this interview. In figure 5 graphical representation shows percentage of respondents know about SDG prior to this survey.

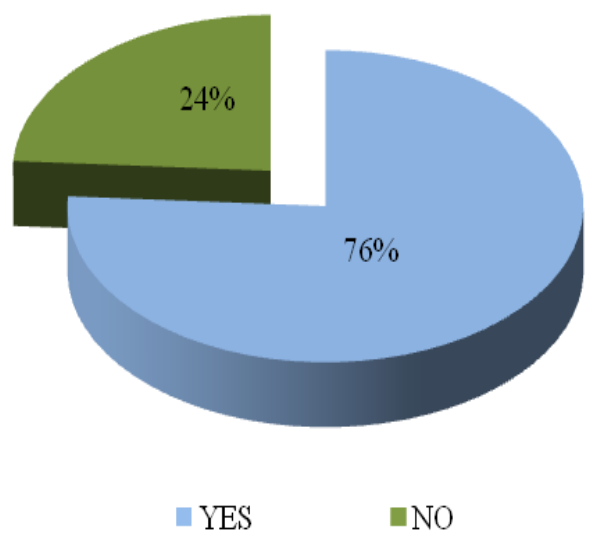

Figure 5: Whether There is Existing Knowledge about the Term SDG Among Respondents?

Table-5 shows the percentage of respondents already have existing knowledge about SDG prior to this survey.

\section{Source of Knowledge about SDG for First Time}

The respondents were asked to choose the source of knowledge about SDG or from where they heard the term "Sustainable Development Goal" for the first time. In the figure-6 graphical representation denotes the percentage of respondents having source of knowledge selected in the given options of question. 


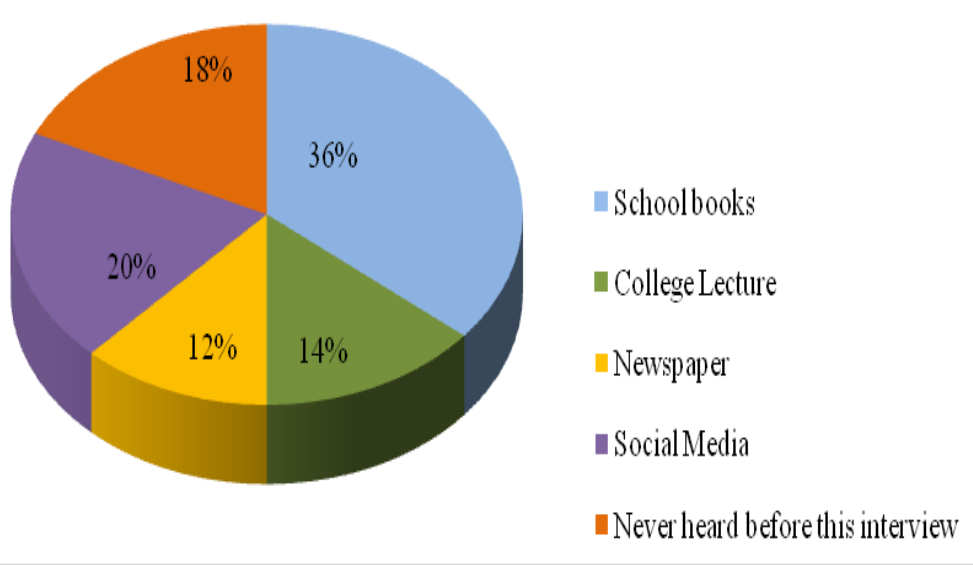

Figure 6: Source of Knowledge about SDG for First Time

Table-6 is given below which gives the percentage of respondents who has chosen the given options of sources in the question.

\section{Level of Interest in Elements of SDG}

Respondents were asked to choose the elements of SDG from the given list of options in the question that interest them most. Figure-7 represent graphically the percentage of respondents who has chosen the options given in the question.

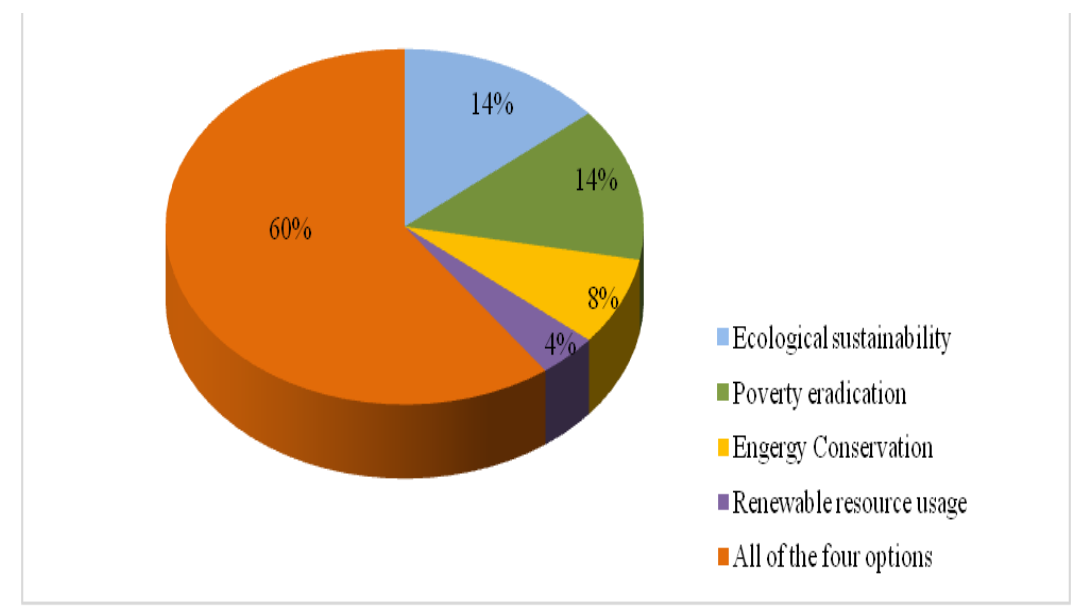

Figure 7: Level of Interest in Elements of SDG

Table-7 is given below which shows the percentage of respondents selected different options given in the question as elements of SDG that interest them most.

\section{Participation in Campaign in Promoting SDG in Higher Education to Eradicate Poverty}

Respondents were asked whether they have ever participated in any campaign to promote SDG in higher education to eradicate poverty. Figure- 8 shows graphical representation of percentage of respondents participated in campaign in promoting SDG in higher education level to eradicate poverty. 


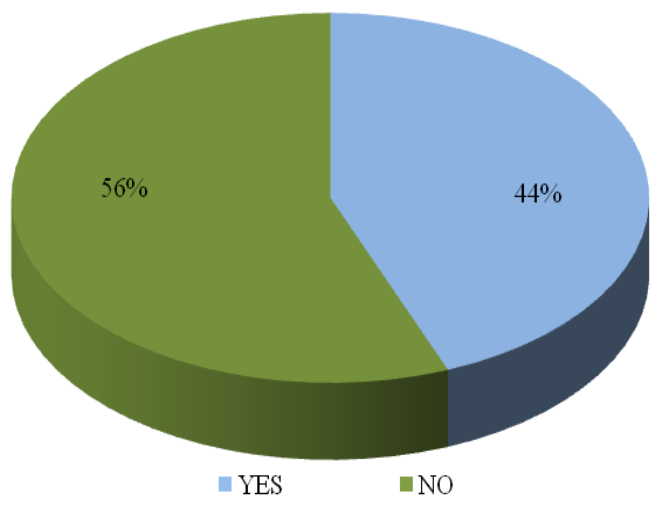

Figure 8: Participation in Campaign in Promoting SDG in Higher Education to Eradicate Poverty

Table- 8 shows the percentage details of respondent participated in campaign to promote SDG in higher education level to eradicate poverty.

\section{Participate in Hastag Movement against Deforestation and Save Planet Earth}

Respondents were asked if they have participated in any hastag movement to save planet earth or against deforestation. Figure-9 represent graphically the percentage of respondents participated in hastag movement in virtual world to save planet earth and against deforestation.

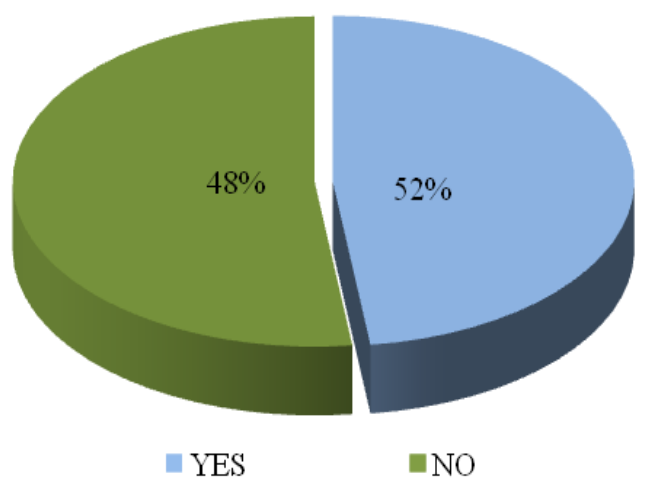

Figure 9: Participate in Hastag Movement against Deforestation and Save Planet Earth

Table-9 is given below which gives the percentage details of respondents participated in hastag movement against deforestation and save planet earth.

\section{Ways Followed by Respondents to Show their Support and Active Participation in Bringing Development without Replenishing the Natural Resources}

Respondents were asked to select their way of participating in bringing development without replenishing the natural resources from the list of answers. Graphical representation shows the percentage of respondents selected various answers from the list. It is seen that nearly $64 \%$ of respondents are passive participant and are only interested in participation through virtual media. 

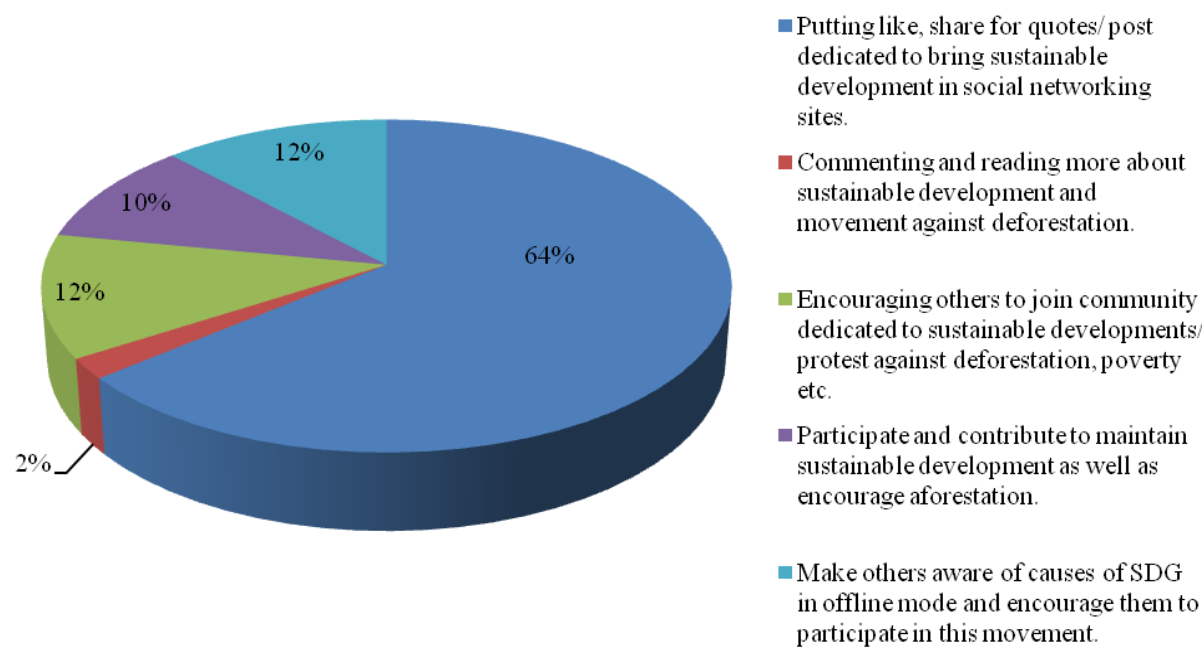

- Particip ate and contribute to maintain sustainable development as well as encourage aforestation.

Make others aware of causes of SDG in offline mode and encourage them to particip ate in this movement

Figure 10: Ways Followed by Respondents to Show their Support and Active Participation in Bringing Development without Replenishing the Natural Resources

Table 10 shows the details of respondents' answer related to said question.

These survey data reveals that younger generation especially undergraduate and post graduate students are well exposed to social media. In this survey their social media behaviour is also studied like which are the social media they are fond of and what activity they perform in the social media especially social networking sites. The survey also showed how social media especially social networking sites are becoming popular medium of SDG awareness among students in higher education even though they have heard the term SDG in their school level. The education policy of environment and sustainable development education has enhanced this level of awareness among school students. At higher education level students are adults and free enough to decide and actively participate in promoting SDG with the use of their previous existing knowledge of SDG. Moreover hastag activism in social medium has gained momentum in present time so students participation in this movement to promote SDG has escalate SDG importance to general mass. Therefore, the current survey and study reveals that new media plays a pivotal role in this decade to enhance SDG awareness promotion to future generation and indulge them to participate in various campaigns related to SDG.

There is limitation in current research study like there is lack of literature on social media usage in promoting SDG among students in higher education level. Also there is lack of literature on how media plays pivotal role in SDG campaign awareness among generation next.

\section{CONCLUSIONS}

In fine the outcome of the research reveals that SDG is ultimate future of every country and United Nation has given utmost priority to it. Thus, enhance its' awareness program at various level through various medium. Out of which social media which emerged as new media of recent times has played important role in spreading awareness about SDG among students in higher education level especially in developing country like India. In suburban region of Kolkata it could be noticed that students are were exposed to social media and are participative in virtual world about issues related to SDG. Now, the question rises if they participate knowingly or unknowingly. Further research can be done on this line to find whether the students in higher education level participate in SDG promotion campaign through virtual world are aware about the issues of SDG. Moreover this research paper focuses mostly on how social networking sites influence and 
promote awareness among students of higher education level in India but it has not covered the role of mobile based social media apps like watsapp, tick tock, messenger etc. to promote SDG awareness so further research can be done in this area.

\section{REFERENCES}

1. Tilbury, Daniella. "Environmental education for sustainability: Defining the new focus of environmental education in the 1990s." Environmental education research 1.2 (1995): 195-212.

2. Adu, E. O., Emunemu, B. O., \& Oshati, T. (2014). The Role of Information and Communication Technology (ICT) and Higher Education in Sustainable Development. Journal of Communication, 5(2), 181-190.

3. Bessant, S. E., Robinson, Z. P., \& Ormerod, R. M. (2015). Neoliberalism, new public management and the sustainable development agenda of higher education: history, contradictions and synergies. Environmental Education Research, 21(3), 417-432.

4. Landorf, H., Doscher, S., \& Rocco, T. (2008). Education for sustainable human development: Towards a definition. School Field, 6(2), 221-236.

5. Background of the Sustainable Development Goals. (n.d.). Retrieved from https://www.undp.org/content/undp/en/home/sustainable-development-goals/background/

$6 \quad$ Sustainable Development Goals:. Sustainable Development Knowledge Platform. (n.d.). Retrieved from https://sustainabledevelopment.un.org/?menu=1300

\section{APPENDIX-1.1}

Table 1: Gender Ratio of Social Media usage of Students at University Level

\begin{tabular}{|c|c|c|c|}
\hline & MALE & FEMALE & TOTAL \\
\hline YES & 40 & 60 & 100 \\
\hline NO & 0 & 0 & 0 \\
\hline
\end{tabular}

Table 2: Most Popular Social Media to the Students

\begin{tabular}{|l|c|c|c|}
\hline & \multicolumn{1}{|c|}{ Total Respondants } & Percentage & Rank \\
\hline Facebook & $1=60,2=20,3=10,4=6,5=4$ & $60 \%$ & $1 \mathrm{st}$ \\
\hline Instagram & $1=40,2=25,3=15,4=12,5=8$ & $40 \%$ & 2 nd \\
\hline Google+ & $1=30,2=15,3=20,4=15,5=10$ & $30 \%$ & $3 \mathrm{rd}$ \\
\hline Twitter & $1=20,2=22,3=16,4=26,5=16$ & $20 \%$ & 4 th \\
\hline LinkedIn & $1=10,2=15,3=20,4=30,5=25$ & $10 \%$ & 5 th \\
\hline
\end{tabular}

Table 3: Topic Interested Most to the Students in Social Networking Sites

\begin{tabular}{|l|c|}
\hline Educational & 7 \\
\hline Lifestyle & 44 \\
\hline Environmental effect & 8 \\
\hline Scientific Progress & 10 \\
\hline Social issues & 31 \\
\hline
\end{tabular}

Table 4: Participation in Virtual Community Dedicated to Environment Protection

\begin{tabular}{|l|c|}
\hline YES & 40 \\
\hline NO & 60 \\
\hline TOTAL & $\mathbf{1 0 0}$ \\
\hline
\end{tabular}


Table 5: Whether there is Existing Knowledge about the Term SDG?

\begin{tabular}{|l|c|}
\hline YES & 76 \\
\hline NO & 24 \\
\hline TOTAL & $\mathbf{1 0 0}$ \\
\hline
\end{tabular}

Table 6: Source of Knowledge about SDG for First Time

\begin{tabular}{|c|c|}
\hline School books & 36 \\
\hline College Lecture & 14 \\
\hline Newspaper & 12 \\
\hline Social Media & 20 \\
\hline Never heard before this interview & 18 \\
\hline Total & 100 \\
\hline
\end{tabular}

Table 7: Level of Interest in Elements of SDG

\begin{tabular}{|c|c|}
\hline Ecological sustainability & 14 \\
\hline Poverty eradication & 14 \\
\hline Engergy Conservation & 8 \\
\hline Renewable resource usage & 4 \\
\hline All of the four options & 60 \\
\hline Total & 100 \\
\hline
\end{tabular}

Table 8: Respondents' Participation in Campaign in Promoting SDG in Higher Education to Eradicate Poverty

\begin{tabular}{|l|c|}
\hline YES & 44 \\
\hline NO & 56 \\
\hline TOTAL & $\mathbf{1 0 0}$ \\
\hline
\end{tabular}

Table 9: Participate in Hastag Movement against Deforestation and Save Planet Earth

\begin{tabular}{|l|c|}
\hline YES & 48 \\
\hline NO & 52 \\
\hline TOTAL & $\mathbf{1 0 0}$ \\
\hline
\end{tabular}

Table 10: Way Followed by Respondents to Show their Support and Active Participation in Bringing Development without Replenishing the Natural Resources

\begin{tabular}{|c|c|}
\hline $\begin{array}{l}\text { Putting like, share for quotes/ post dedicated to bring sustainable } \\
\text { development in social networking sites. }\end{array}$ & 64 \\
\hline $\begin{array}{l}\text { Commenting and reading more about sustainable development and } \\
\text { movement against deforestation. }\end{array}$ & 2 \\
\hline $\begin{array}{l}\text { Encouraging others to join community dedicated to sustainable } \\
\text { developments/ protest against deforestation, poverty etc. }\end{array}$ & 12 \\
\hline $\begin{array}{l}\text { Participate and contribute to maintain sustainable development as } \\
\text { well as encourage aforestation. }\end{array}$ & 10 \\
\hline $\begin{array}{l}\text { Make others aware of causes of SDG in offline mode and } \\
\text { encourage them to participate in this movement. }\end{array}$ & 12 \\
\hline Total & 100 \\
\hline
\end{tabular}




\section{APPENDIX-1.2}

Questionnaire for Survey

Knowledge-Based Social Media usage in SDG Awareness Survey Interview Questions and Answers

(The students are need to filled up this questionnaire. This questionnaire aimed to bring out how the university level students (both post graduate and under graduate) are assessing social media like facebook for the concept of "SDG" or sustainable development goal. All are requested to go through the questions properly and carefully fill it up. The questionnaire is purely meant for academic purpose.)

\section{Personal Data}

Name:

Age: Gender:

Educational Qualification: Undergraduate student/ Post-graduate student

Department:

Email-id -

Phone no. -

\section{General Study of New Media Usage Habit}

1. Do you use social media?

$$
\text { Yes/No }
$$

2. What are the social media you use? Rank it in the scale of 5 from the list.

LinkedIn, Facebook, Instagram, Twitter, Google+

3. Which topic interest you most in social networking sites?

Educational/ Lifestyle/ Environmental effect/ Scientific Progress/ Social issues

4. Do you participate in virtual community dedicated to protecting environment?

Yes/ No

\section{Assessment of Knowledge And Awareness About SDG}

5. Do you know about SDG or sustainable development goal?

$$
\text { Yes/ No }
$$

6. Which elements of SDG interest you most?

Ecological sustainability/ Poverty eradication / Energy conservation/ renewable resource usage/ All of the above

7. From where do you hear this term SDG (Sustainable Development Goal) for first time?

School books/ College lecture/ Newspaper / social media / Never heard before this interview 
8. Do you participate in any campaign in promoting sustainable development goal in higher education to eradicate poverty?

Yes/ No

9. Do you participate in virtual community or hastag movement against deforestation and save planet earth?

Yes/ No

10. What way do you follow to show your support and active participation in bringing development without replenishing the natural resources?

- $\quad$ Putting like, share for quotes/ post dedicated to bring sustainable development in social networking sites.

- Commenting and reading more about sustainable development and movement against deforestation.

- Encouraging others to join community dedicated to sustainable developments/ protest against deforestation, poverty etc.

- Participate and contribute to maintain sustainable development as well as encourage a forestation.

- Make others aware of causes of SDG in offline mode and encourage them to participate in this movement. 